\title{
Individualised therapy of angiotensin converting enzyme (ACE) inhibitors in stable coronary artery disease: overview of the primary results of the PERindopril GENEtic association (PERGENE) study
}

\author{
J. J. Brugts • M. P. M. de Maat • A. H. J. Danser • \\ E. Boersma • M. L. Simoons \\ Published online: 18 June 2011 \\ (C) The Author(s) 2011. This article is published with open access at Springerlink.com
}

\begin{abstract}
In patients with stable coronary artery disease (CAD) without overt heart failure, ACE inhibitors are among the most commonly used drugs as these agents have been proven effective in reducing the risk of cardiovascular events. Considerable individual variations in the blood pressure response to ACE inhibitors are observed and as such heterogeneity in clinical treatment effect would be likely as well. Assessing the consistency of treatment benefit is essential for the rational and cost-effective prescription of ACE inhibitors. Information on heterogeneities in treatment effect between subgroups of patients could be used to develop an evidence-based guidance for the installation of ACE-inhibitor therapy. Obviously, therapy should only be applied in those patients who most likely will benefit. Attempts to develop such treatment guidance by using clinical characteristics have been unsuccessful. No heterogeneity in risk reduction by ACE inhibitors has been observed in relation to relevant clinical characteristics. A new approach to such 'guided-therapy' could be to integrate more patient-specific characteristics such as the
\end{abstract}

The presented research project is supported by the Netherlands Heart Foundation grant number NHS 2005-B219 for Dr. J.J. Brugts

J. J. Brugts $(\bowtie) \cdot$ E. Boersma $\cdot$ M. L. Simoons

Department of Cardiology, Erasmus MC Thoraxcenter,

's Gravendijkwal 230,

3015 CE, Rotterdam, the Netherlands

e-mail: j.brugts@erasmusmc.nl

M. P. M. de Maat

Department of Hematology, Erasmus MC,

Rotterdam, the Netherlands

A. H. J. Danser

Department of Pharmacology, Erasmus MC,

Rotterdam, the Netherlands patients' genetic information. If proven feasible, pharmacogenetic profiling could optimise patients' benefit of treatment and reduce unnecessary treatment of patients. Cardiovascular pharmacogenetic research of ACE inhibitors in coronary artery disease patients is in a formative stage and studies are limited. The PERGENE study is a large pharmacogenetic substudy of the EUROPA trial, aimed to assess the achievability of pharmacogenetic profiling. We provide an overview of the main results of the PERGENE study in terms of the genetic determinants of treatment benefit and blood pressure response. The main results of the PERGENE study show a pharmacogenetic profile related to the treatment benefit of perindopril identifying responders and non-responders to treatment.

Keywords Pharmacogenetics - ACE inhibitors . Perindopril · Gene · Haplotype · Polymorphism · Coronary artery disease $\cdot$ Secondary prevention

The angiotensin-converting enzyme (ACE) inhibitors competitively block the conversion of angiotensin-I (AT-1) into angiotensin-II (AT-II). This blockade results in a decrease in circulating and local levels of AT-II, thereby inhibiting the main effects of AT-II which are arteriolar vasoconstriction and water and salt retention. ACE inhibitors decrease the transformation of bradykinin in inactive peptides, thereby increasing the levels of bradykinin [1,2]. The increase in levels of bradykinin leads to a higher release of nitric oxide and prostaglandins with vasodilatory effects on vessel walls $[2,3]$.

The efficacy of ACE inhibitors has been demonstrated by several large clinical trials in a broad variety of patients at different levels of risk [4-11]. Nowadays, the use of ACE inhibitors is recommended in guidelines on the management of hypertension, stable coronary artery disease (CAD), myocardial infarction (MI), and heart failure, and 
therefore ACE inhibitors are among the most frequently prescribed drugs in these patient groups [12-14].

This review is primarily focused on patients with stable CAD and the ACE inhibitor perindopril as studied in the EUROPA trial and its substudy the PERGENE study [10, 15].

\section{The EUROPA trial}

The EURopean trial On reduction of cardiac events with Perindopril in patients with stable coronary Artery disease (EUROPA) studied the ACE inhibitor perindopril in a population with stable coronary artery disease with preserved left ventricular function [10]. In EUROPA, 12,218 patients were randomly assigned perindopril $8 \mathrm{mg}$ once daily $(n=6110)$ or matching placebo $(n=6108)$. The primary endpoint was a composite of cardiovascular mortality, myocardial infarction, or cardiac arrest. During a mean follow-up of 4.2 years, perindopril was associated with a reduction in the incidence of the primary endpoint from $9.9 \%$ in placebo to $8.0 \%$ in perindopril-treated patients, which yielded a $20.5 \%$ relative risk reduction (HR 0.80; 95\% CI 0.71-0.91) (Fig. 1) [10].

One would like to guide such prolonged prophylactic treatment to only those patients who will encounter treatment benefit. Heterogeneity in the clinical treatment effect of ACE inhibitors might be used to guide ACE inhibitor therapy only to those patients most likely to benefit from such therapy and, by doing so, the overall clinical efficacy could be increased (lower number needed to treat). Tailored ACE inhibitor therapy will improve patient benefit, and reduce unnecessary healthcare costs and side effects. Several analyses have been performed to test the consistency of the treatment benefit of ACE inhibitors among patient subgroups based on clinical characteristics which are discussed below [16-20].

\section{Guiding ACE inhibitor treatment based on clinical characteristics}

Using the EUROPA trial data, a risk model based on baseline clinical characteristics related to the primary endpoint was developed to predict outcome in these patients depending on the patient's baseline risk [17]. However, the treatment benefit of perindopril was consistent across different risk categories and therefore not modified by the level of baseline risk. Another post-hoc analysis of the EUROPA study demonstrated that renal insufficiency does not modify the treatment benefit of ACE inhibitors $[18,19]$. Finally, in a recent meta-analysis which combined several trials investigating the ACE inhibitor perindopril in 29,463 patient with vascular disease (stable
CAD, cerebrovascular disease and diabetes), a consistent treatment effect of ACE inhibitor based regimens was demonstrated, independent of clinical characteristics or baseline blood pressure levels (Fig. 2) [20]. We have concluded that, although many studies have been performed to test the heterogeneity of treatment benefit of ACE inhibitors in patients with stable CAD, based on these studies it does not appear to be feasible to guide ACE inhibitor therapy to specific subgroups of patients based only on clinical characteristics.

\section{New approaches to guiding ACE inhibitor therapy}

We used more patient-specific characteristics such as patients' genetic information (DNA). Pharmacogenetics is aimed to understand why some drugs work better for some people than others and why some people are more likely to experience side effects. If genetic factors are indeed related to drug response, pharmacogenetic profiling might be a new way to reach significant advances in individualised cardiovascular medicine.

Currently, pharmacogenetic research of ACE inhibitors is rare. In general, it is expected that the response of a patient to therapy can be influenced by several types of genetic factors: 1) Genetic factors causing differences in drug absorption and metabolic clearance are highly relevant (pharmacokinetics); however; this is still a relatively unexplored field for ACE inhibitors. 2) Genetic factors within the direct pharmacodynamic pathway that is affected by the ACE inhibitors, the renin-angiotensin-aldosterone system (RAAS), and bradykinin gene pathways are likely to affect the clinical efficacy of ACE inhibitors, including receptors and signal transduction molecules. Also, variations within genes of the RAAS and related systems may influence atherosclerosis and thereby inherent differences in the susceptibility to the antiatherosclerotic properties of ACE inhibitors [21, 22].

The vast majority of prior studies focused on only one or two polymorphisms, the angiotensin-converting enzyme (ACE) I/D polymorphism and the M235T polymorphism in the angiotensinogen (AGT) gene. This is a severe limitation and does not justify the complexity of the renin-angiotensin system. Because of limited study sample size and power, results have been inconsistent. Limited prior research with ACE inhibitors in stable CAD has been performed at largescale or in a randomised trial setting.

\section{Concept of pharmacogenetic research to individualise medicine}

The concept of pharmacogenetic research to individualise medicine is emerging rapidly and is clinically highly relevant. Several successes of this approach have recently 


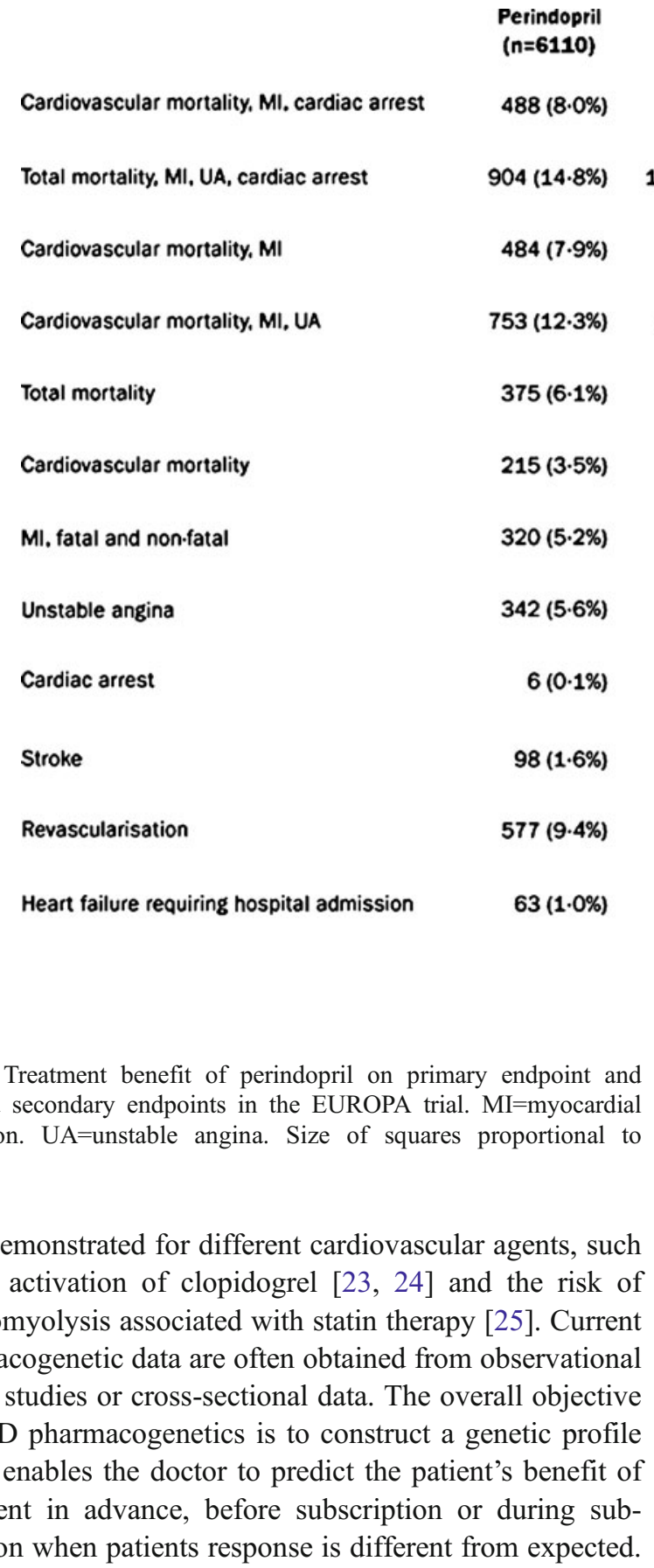

Fig. 1 Treatment benefit of perindopril on primary endpoint and selected secondary endpoints in the EUROPA trial. MI=myocardial infarction. $U A=$ unstable angina. Size of squares proportional to

been demonstrated for different cardiovascular agents, such as the activation of clopidogrel $[23,24]$ and the risk of rhabdomyolysis associated with statin therapy [25]. Current pharmacogenetic data are often obtained from observational cohort studies or cross-sectional data. The overall objective of CVD pharmacogenetics is to construct a genetic profile which enables the doctor to predict the patient's benefit of treatment in advance, before subscription or during subscription when patients response is different from expected.

\section{The PERGENE study}

The PERindopril GENEtic association study (PERGENE) is a pharmacogenetic substudy of the main EUROPA trial [15]. The PERGENE study aims to assess the practicability of pharmacogenetic profiling of treatment benefit of ACE inhibitors in patients with stable CAD for reasons addressed above. We hypothesised that genetic polymorphism in the RAAS and kininogen-kallikrein-bradykinin pathways influences the treatment benefit of ACE inhibitors in patients with
Placebo

( $n=6108$ )

$603(9 \cdot 9 \%)$

$1043(17 \cdot 1 \%)$

$596(9 \cdot 8 \%)$

$885(14.5 \%)$

$420(6.9 \%)$

$249(4 \cdot 1 \%)$

$418(6 \cdot 8 \%)$

$367(6 \cdot 0 \%)$

$11(0 \cdot 2 \%)$

$102(1 \cdot 7 \%)$

$601(9 \cdot 8 \%)$

$103(1 \cdot 7 \%)$

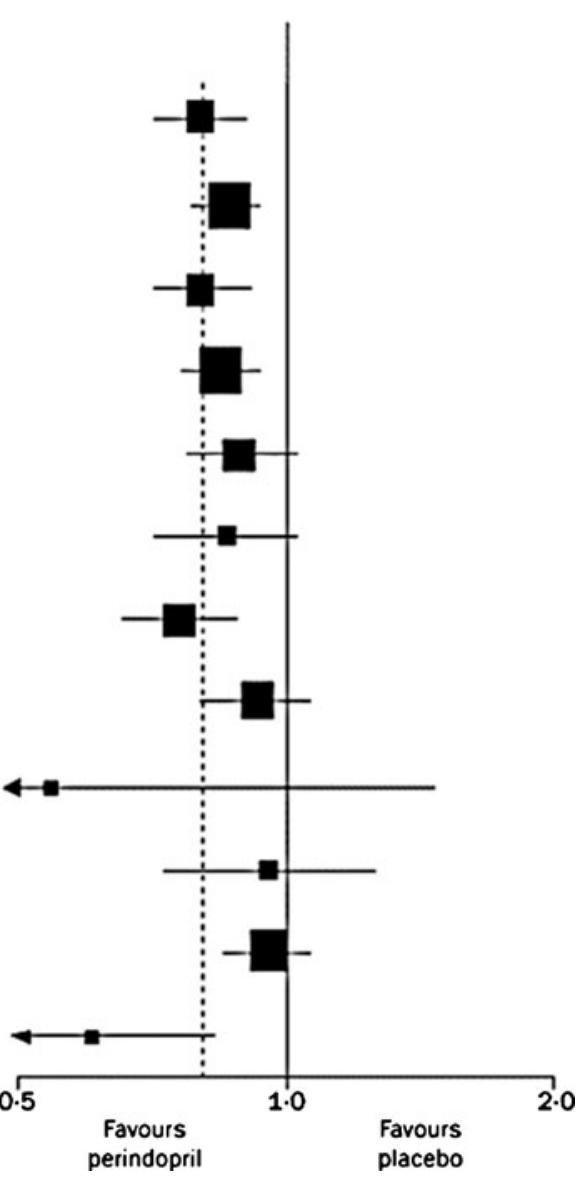

number of patients in that group. Dashed line indicates overall relative risk reduction. Adapted with permission (Lancet 2003; 362: 782-88)

stable CAD. The main outcome measure of PERGENE was the interaction between genetic factors and treatment effect of ACE inhibitors during follow-up. Secondary endpoint was the relation between the genetic determinants and blood pressure and blood pressure reduction to ACE inhibitor therapy [15].

\section{Study design}

Exact details on the study design, SNP selection procedure and statistical analysis can be found elsewhere [15]. In brief, the PERGENE study investigates whether common genetic variation is related to the risk of future events and modifies the treatment effect of perindopril. Written informed consent for performing genetic association analyses was obtained from all patients. A DNA bio-bank was established within the EUROPA trial (at the beginning of the EUROPA study) for the PERGENE substudy [15]. Blood samples were received from 10,060 patients and DNA was successfully isolated from 9454 patients using an automated isolation process (Hamilton NV, USA). Twelve candidate genes within 
Fig. 2 Consistency of treatment benefit of perindopril in patients with vascular disease (meta-analysis of ADVANCE, PROGRESS, EUROPA individual data). MI=myocardial infaction, $\mathrm{CVA}=$ cerebrovascular accident, TIA=transient ischaemic attack. Adapted with permission from Brugts JJ et al. Eur Heart J 2009; 30, 1385-1394

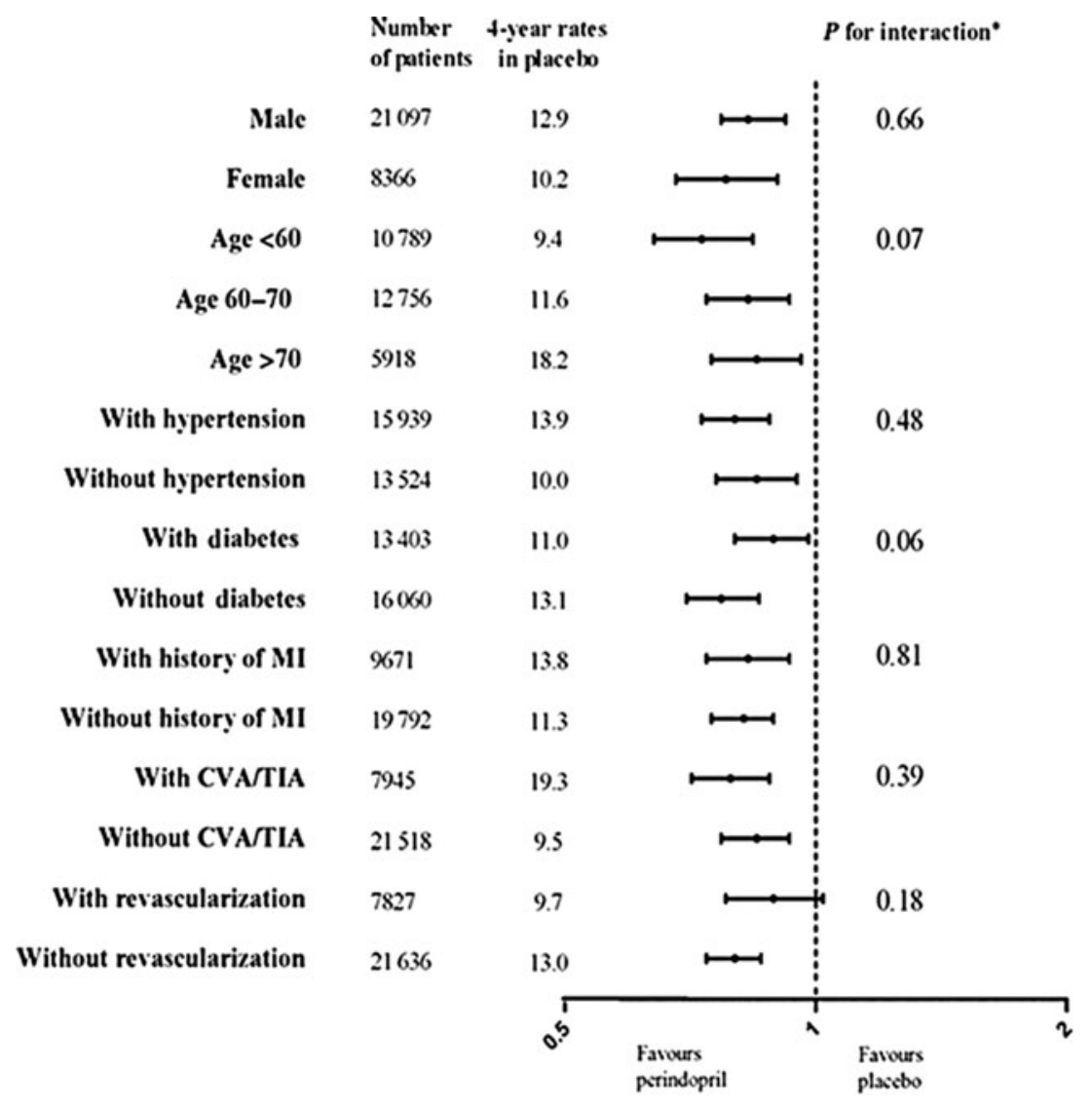

the direct pharmacodynamic pathway of ACE inhibitors, the RAAS and bradykinin systems, were selected for this analysis (Fig. 3). To cover common variation in these 12 candidate genes comprehensively, haplotype-tagging SNPs (ht-SNP) were selected based on the linkage disequilibrium (LD) structure as provided by the public databases of HapMap, PARC, and SeattleSNPs.

The treatment effect of perindopril was defined as the reduction in the event rate of the primary endpoint of the EUROPA trial compared between genotype strata for each SNP. Genotype-treatment interactions were assessed with multivariate Cox proportional hazards regression models. Multiple testing corrections of treatment interaction terms, and estimation of empirical $P$-values, were implemented using Monte Carlo permutation analysis (10,000 permutations) on a per-gene basis.

\section{Results of the PERGENE study}

Pharmacogenetic determinants of clinical treatment effect of ACE inhibitors

In unadjusted analysis, 7 single nucleotide polymorphisms in 4 different candidate genes were significantly associated with the treatment effect of perindopril. In multivariate permutation analysis, 3 of these SNPs, located in the AT1 receptor and $\mathrm{BK} 1$ receptor genes, remained significant modifiers of the treatment benefit of perindopril [26].

In the BK1 receptor gene, rs12050217 was a strong modifier of the treatment benefit of perindopril as presented in Fig. 4. Additionally, in the AT1 receptor gene, rs275651 and rs5182 significantly modified the treatment benefit of perindopril. Genetic determinants of treatment benefit of perindopril have not been demonstrated previously [26].

We constructed a pharmacogenetic risk score by combining the unfavourable alleles of the treatment effect modifying SNPs (Fig. 5) [26]. Unfavourable alleles were associated with diminished treatment effect as observed in the overall study group. The pharmacogenetic risk score demonstrated a decrease in the level of treatment benefit of perindopril with an increasing number of unfavourable alleles. In patients with no unfavourable alleles, a much more pronounced treatment benefit was observed as compared with the overall study result (which yielded a $20 \%$ relative risk reduction). By combining pharmacogenetic risk scores, we observed that the treatment benefit was concentrated in about 3 out of 4 of the patients and absent in 1 out of 4 of the patients [26]. This is the first time that subgroups of responders and non-responders to ACE inhibitor treatment have been identified. An interaction effect of similar direction and magnitude was observed in 


\section{The RAAS and bradykinin pathways}

\section{Candidate}

Genes
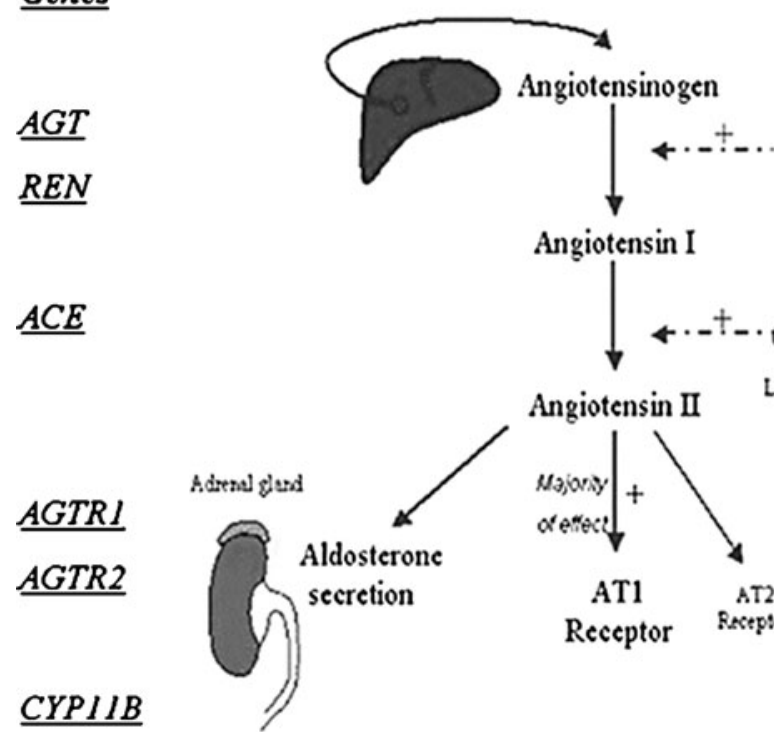

\section{Angiotensin I}

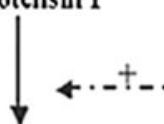

$\underline{C Y P M I B}$

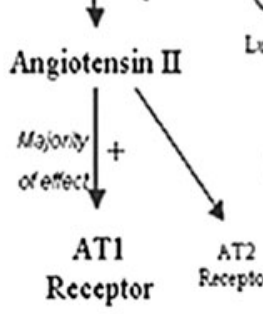

Candidate

Genes
Fig. 3 Selected candidate genes in the renin-angiotensin-aldosterone system and bradykinin pathways. AGT angiotensinogen, REN renin, $A C E$ angiotensin-converting enzyme, $A G T R 1$ angiotensin II receptor type 1, AGTR2 angiotensin II receptor type 2, CYP11B aldosteron

an initial confirmatory analysis of 1051 patients with cerebrovascular disease from the PROGRESS trial [26].

In the patients who were identified as responders and non-responders with pharmacogenetic profiling, no differences in clinical characteristics were observed in PERGENE [26]. Also intermediate phenotypes such as blood pressure and blood pressure reduction levels were comparable between responders and non-responders [26]. Thus, the observed treatment interaction cannot be explained by

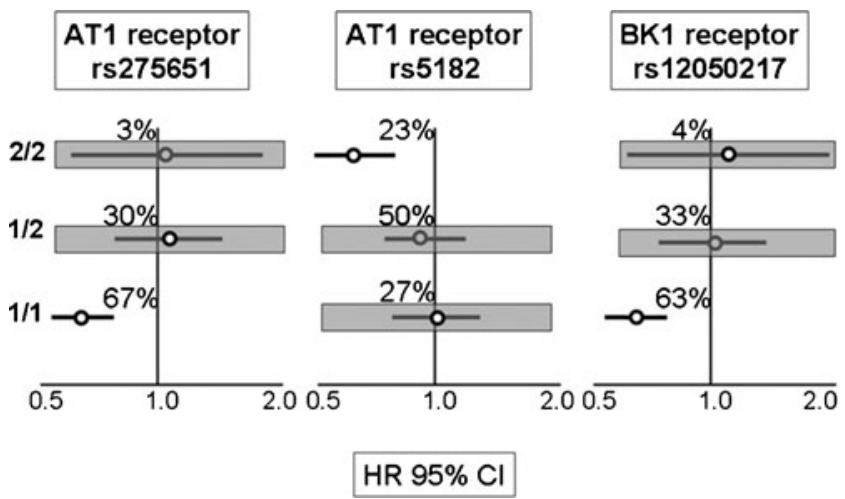

Fig. 4 Treatment effect modifying SNPs in PERGENE. 1/1=homozygous common allele, $1 / 2=$ heterozygous, $2 / 2=$ homozygous common allele. Percentages correspond to the number of patients within each group according to genotype. The $\mathrm{X}$-axis corresponds to the hazard ratio and 95\% CI estimates and Y-axis to genotype category. Adapted with permission from Brugts JJ, et al. Eur Heart J. 2010 Aug;31(15):1854-64 synthase, $K L K$ kallikrein, $K N G$ kininogen, $B D K R B 1$ bradykinin receptor type $1, B D K R B 2$ bradykinin receptor type 2, eNOS3 nitric oxide synthase. Adapted with permission from Brugts JJ et al. Cardiovasc Drugs Ther 2009;23:171-181

clinical differences between the genotypes but can only be prescribed to the net genetic difference between patients.

RAAS genes in relation to hypertension and blood pressure reduction to ACE inhibitors

As hypertension is a strong intermediate phenotype of $\mathrm{CAD}$, we investigated whether genetic variations in the

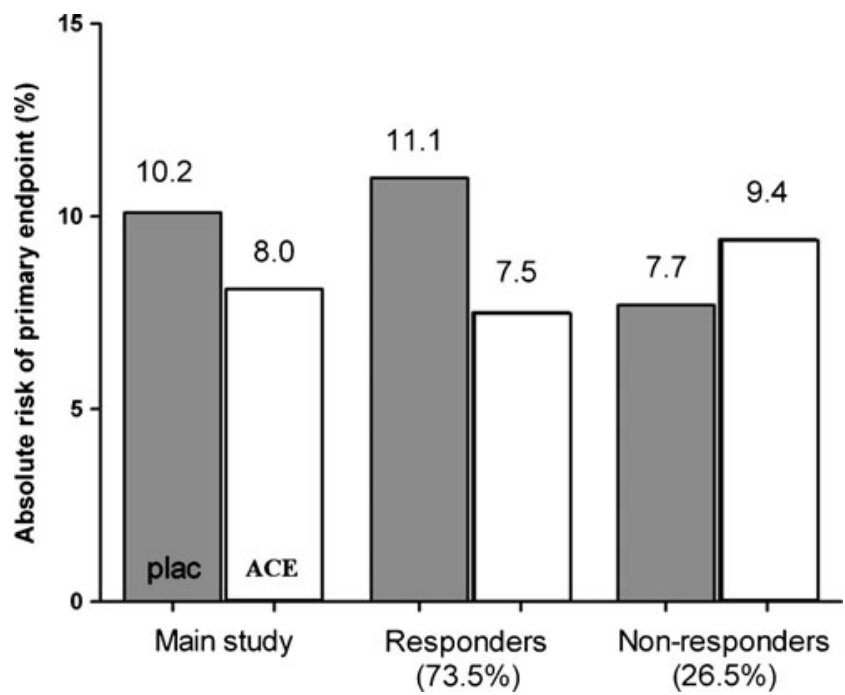

Fig. 5 Treatment effect according to the pharmacogenetic profile categories. Responders $=<3$ unfavourable alleles, non-responders $\geq 3$ unfavourable alleles. Adapted with permission from Brugts JJ, et al. Eur Heart J. 2010 Aug;31(15):1854-64 
cascade of RAAS/bradykinin system genes are involved in blood pressure and whether such genetic variations determine the $\mathrm{BP}$ response to ACE inhibitor therapy which is highly variable between patients [27]. A differential BP effect determined by genetic factors may give insight into their clinical effects.

The PERGENE study demonstrated that the genetic variants in the ACE, angiotensinogen and prorenin gene were important determinants of hypertension at baseline. These genetic determinants of hypertension in the RAAS system were also observed in the two replication cohorts of the PROGRESS trial (patients with cerebrovascular disease) and ERGO study (relatively healthy elderly subjects) [27] (Fig. 6). However, the blood pressure response to the ACE inhibitor perindopril was not modified by the genetic polymorphisms in the RAAS or bradykinin pathway.

These findings are consistent with prior subgroup analyses on blood pressure and $\mathrm{BP}$ reduction by $\mathrm{ACE}$ inhibitor therapy demonstrating that the clinical benefits are independent of blood pressure and the amount of BP reduction [20, 28, 29].

To strengthen our results, the Blood Pressure Lowering Treatment Trialists' Collaboration (BPLTTC) consortium studied the blood pressure dependent and independent effects of ACE inhibitors in 146,838 patients and confirmed that a beneficial effect up and above blood pressure reduction is present [29]. Substudies of EUROPA have investigated the additional effects of ACE inhibitors and have established that ACE inhibitors have additional effects beyond the blood pressure reduction alone, such as the improvement of endothelial function, improvement of the neurohumoral balance, and reduction of unfavourable remodelling of the coronary arteries [30, 31].

Potential mechanisms of the pharmacogenetic profile of treatment benefit

In summary, the PERGENE study identified new genetic determinants of clinical treatment benefit of ACE inhibitors, but these genetic determinants do not mediate these effects through change in BP as these SNPs did not pop up in the analysis on BP reduction $[26,27]$. The treatment effect modifying SNPs was particularly located in the AT1 and BK1 receptors. The SNPs in the AT1 receptor were located in the promoter (rs275651) and exon 4 (rs5182) on chromosome 3, the SNP in the BK1 receptor gene on chromosome 14 was located in an intron region. All three SNPs were important tagging SNPs within their candidate gene [26]. Functionality of these SNPs is at this moment unknown, but more basic research has been started based on these findings. As the AT1 receptor is involved in the direct effects of angiotensin II, it can be hypothesised that genetic variants in the AT1 receptor will influence the response to an ACE inhibitor. The exact role of the BK1

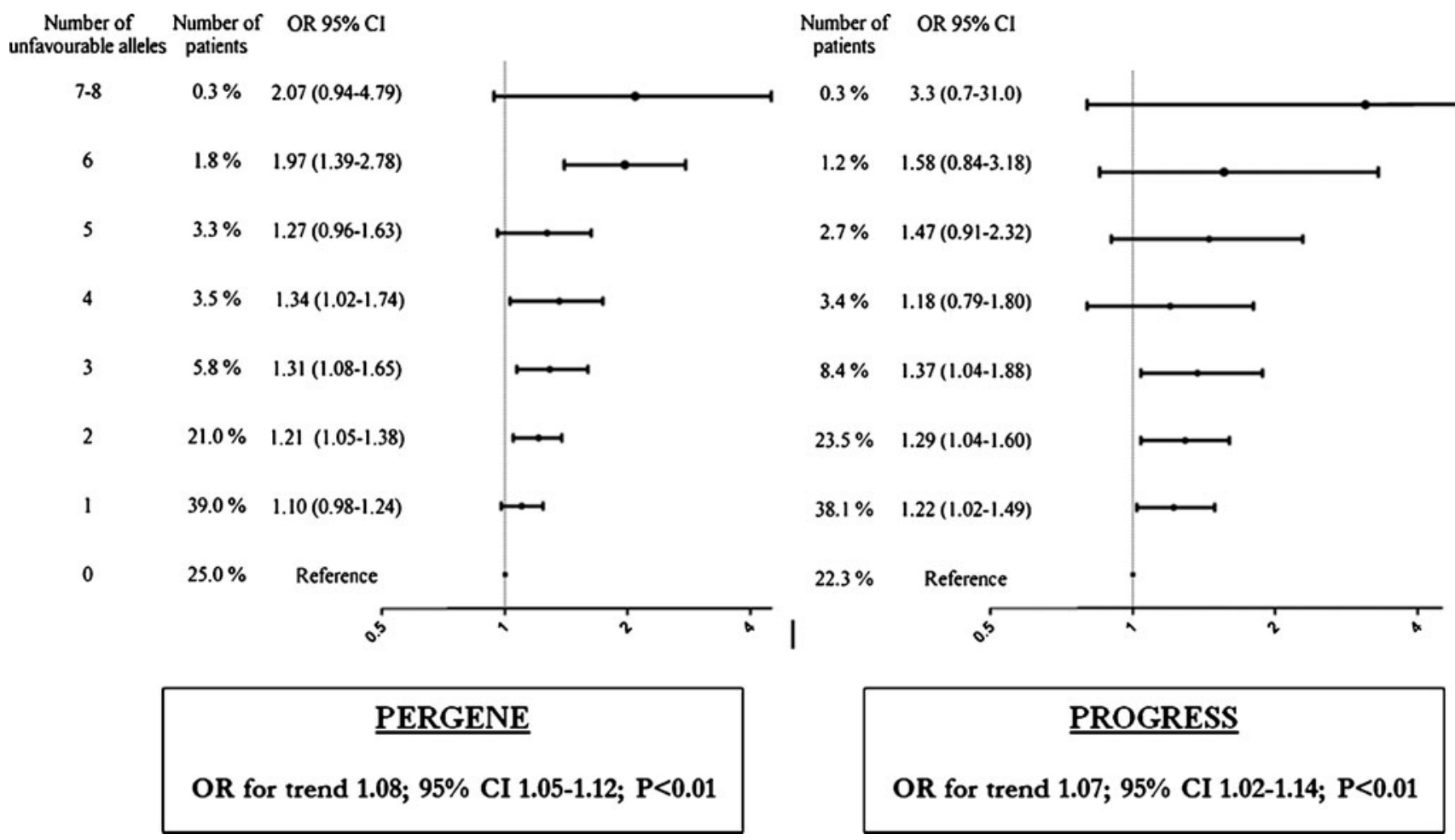

Fig. 6 Cumulative effects of the identified SNPs on the prevalence of hypertension. OR hypertension. OR odds ratio CI confidence interval. Adapted with permission from Brugts JJ, et al. J Hypertens. 2011 Mar;29(3);509-19 
receptor, on the other hand, is less well established. Bradykinin is a potent vasodilator that also induces antiatherosclerotic and antithrombotic effects, which are mediated by BK2 receptors. Previous studies indicated that the clinical benefit of ACE inhibitors depends, at least in part, on BK2 receptor activation [32]. In the past year, more data are emerging on the effect of the BK1 receptor, the effects of which are less well known. BK1 receptors are weakly expressed under physiological conditions, but are strongly induced in response to pathological conditions and/or RAAS blockade [33, 34]. Recent reports indicate that BK1 receptor deficiency predisposes to atherosclerosis [35] and kinins and the BK1 receptor plays an important deleterious role in this process [36]. Interestingly, it has been suggested that BK1 receptors are directly activated by ACE inhibitors (thus resulting in an increase in endothelial NO release, for instance in the heart [37,38], by which they do contribute to the cardioprotective beneficial effects of $\mathrm{ACE}$ inhibitors, but this has not been uniformly confirmed by others [39]. Therefore, a more likely possibility is that the upregulated BK1 receptors are activated by their endogenous ligand during ACE inhibition. Such activation results in the hypotensive [40], cardioprotective [37] and cerebroprotective [41] effects of kinins, as observed in animals, and one could speculate that patients with genetic defects in their BK1 receptor display a diminished response to ACE inhibition with regard to kinins. Indeed, in our study we observed that especially patients with the minor allele variants of the BK1 receptor were relatively insensitive or resistant to the beneficial effect of the ACE inhibitor. Clearly, more work is needed to support this interesting concept.

Still, the lack of a blood pressure related effect of the 3 identified SNPs in the treatment effect analysis suggests a different pathway of clinical effect [26, 27] and emphasises more on the bradykinin effects of ACE inhibitors as the blood pressure independent effects of ACE inhibitors is often proposed for the BK pathway [11]. Our analyses may indicate that the up-regulated BK1 receptor in stressed CAD patients may play an important role in the assumed pleiotropic effect of ACE inhibitors. Our findings do support that concept, as it might be speculated that the genetic defects in the BK1 receptor alter the antiatherosclerotic properties of the ACE inhibitor treatment effect which might be an important cornerstone of the treatment benefit besides blood pressure lowering.

\section{Clinical implications: pharmacogenetic breakthrough in the rationale of prescribing medication}

The PERGENE study demonstrated a relative resistance to ACE inhibitors in patients with unfavourable alleles of the AT1 receptor and BK1 receptor genes. Based on the
PERGENE findings, three out of four patients with stable CAD (participating in EUROPA) had an enhanced benefit of ACE inhibitor therapy, and one out of four patients experienced a markedly diminished benefit of treatment with perindopril (non-responders, risk score $\geq 3$ ).

In our pharmacogenetic profile (Table 1) categories of patients with $<3$ and $\geq 3$ unfavourable alleles, relative risk reduction was $33 \%$ (HR 0.67 ; 95\% CI $0.56-0.79$ ) and $+26 \%$ (HR 1.26; 95\% CI 0.97-1.67), respectively. Refraining from treatment with perindopril in this group of patients may considerably reduce healthcare costs and increase overall efficacy of the drug.

In the fictive scenario that only patients with $<3$ unfavourable alleles would have been treated, which compromises $76.5 \%$ of the population, the absolute risk would be reduced from $11.1 \%$ in placebo to $7.5 \%$ in perindopril patients. Likewise, the number needed to treat would decrease from 50 to 32 . Considering the millions of patients treated with ACE inhibitors, this reduction has huge clinical implications and fictively demonstrates the potential of pharmacogenetic profiling of drug response to antihypertensives.

\section{Feasibility of pharmacogenetic profiling of ACE inhibitors}

The PERGENE study is one of the first pharmacogenetic analyses within a randomised clinical trial demonstrating the heterogeneity in treatment benefit of ACE inhibitors. These promising results indicate that the concept of pharmacogenetic profiling is feasible and should be investigated more. Further replication must be sought in other cohorts and replicated in similar patient populations but also in patients at higher risk of events. Additionally, other relevant genetic targets need to be investigated such as genes involved in the metabolism of ACE inhibitors, fe CYP450 genes (pharmacokinetics). However, until now no specific genetic targets for ACE inhibitor metabolism have been demonstrated.

Table 1 Hazard ratios for the pharmacogenetic risk scores and clinical treatment benefit of the ACE inhibitor perindopril

\begin{tabular}{lcc}
\hline Risk scores & Number of patients $(\%)$ & Hazard ratio $(95 \% \mathrm{CI})$ \\
\hline$<1$ & 3584 & $0.58(0.46-0.72)$ \\
2 & 2826 & $0.81(0.63-1.03)$ \\
$\geq 3$ & 2316 & $1.26(0.97-1.67)$ \\
Pharmacogenetic profile & \\
$<3$ & 6410 & $0.67(0.56-0.79)$ \\
$\geq 3$ & 2316 & $1.26(0.97-1.67)$ \\
Overall study & 8726 & $0.80(0.71-0.91)$ \\
\hline
\end{tabular}


We advocate that future large-scale randomised clinical trials should also integrate a pharmacogenetic analysis in their trial design to prospectively test treatment efficacy in a similar way. Pharmacogenetic analyses of clinical trials truly open up a perspective to individualise preventive therapy in patients with cardiovascular disease. Physicians will be able to predict the response to treatment (responders and non-responders) in advance, before starting prescription. 'Individualised therapy' by pharmacogenetic profiling will avoid unnecessary treatment of non-responding patients and considerably reduce healthcare costs.

Acknowledgements Brugts is supported by a grant from the Netherlands Heart Foundation (NHS-2005-B219) and a grant from the Netherlands Organization for Health Research and Development (ZonMW)

Financial disclosure None.

Conflict of interest JJB, MM, JD and EB declare to have no conflict of interest, MLS has received speaker fees and research grants from Servier.

Open Access This article is distributed under the terms of the Creative Commons Attribution Noncommercial License which permits any noncommercial use, distribution, and reproduction in any medium, provided the original author(s) and source are credited.

\section{References}

1. Pellacani A, Brunner HR, Nussberger J. Plasma kinins increase after angiotensin enzyme inhibition in human subjects. Clin Sci (Lond). 1994;87:567-74.

2. Ferrari R. Angiotensin-converting enzyme inhibition in cardiovascular disease: evidence with perindopril. Expert Rev Cardiovasc Ther. 2005;3:15-29.

3. Brugts JJ, den Uil CA, Danser AHJ, et al. The renin-angiotensinaldosterone system: approaches to guide angiotensin-converting enzyme inhibition in patients with coronary artery disease. Cardiology. 2009;112:303-12.

4. Pfeffer MA, Braunwald E, Moye LA, et al. SAVE investigators. Effect of captopril on mortality and morbidity in patients with left ventricular dysfunction and myocardial infarction: results of the survival and ventricular enlargement trial. $\mathrm{N}$ Engl $\mathrm{J}$ Med. 1992;327:669-77.

5. The SOLVD investigators. Effect of enalapril on survival in patients with reduced left ventricular ejection fractions and congestive heart failure. N Engl J Med. 1991;325:293-302.

6. The Acute Infarction Ramipril Efficacy (AIRE) study investigators. Effect of ramipril on mortality and morbidity of survivors of acute myocardial infarction with clinical evidence of heart failure. Lancet. 1993;342:821-8.

7. Torp-Pedersen C, Kober L, TRACE Study Group. Effect of ACE inhibitor trandolapril on life expectancy of patients with reduced left-ventricular function after acute myocardial infarction. Lancet. 1999;354:9-12.

8. The Heart Outcomes Prevention Evaluation study investigators. Effects of an angiotensin-converting enzyme inhibitor, ramipril, on cardiovascular events in high-risk patients. $\mathrm{N}$ Engl $\mathrm{J}$ Med. 2000;342:145-53.

9. The PEACE Trial Investigators. Angiotensin-converting-enzyme inhibition in stable coronary artery disease. $\mathrm{N}$ Engl $\mathrm{J}$ Med. 2004;351:2058-68.

10. The European Trial on Reduction of Cardiac Events with Perindopril in Patients with Stable Coronary Artery Disease investigators. Efficacy of perindopril in reduction of cardiovascular events in stable coronary artery disease: randomized, doubleblind, placebo controlled, multicentre trial (the EUROPA study). Lancet 2003;362:782-8.

11. Brugts JJ, Ferrari R, Simoons ML. Angiotensin-converting enzyme inhibition by perindopril in the treatment of cardiovascular disease. Exp Rev Cardiovasc. 2009;7(4):345-60.

12. The Task Force on the Management of Stable Angina Pectoris of the European Society of Cardiology. Guidelines on the management of stable angina pectoris. Eur Heart J. 2006;27:134181.

13. Wood D, DeBacker G, Faergam O, et al. Prevention of coronary disease in clinical practice: recommendation of the second Joint Task Force of European and other societies on Coronary Prevention. Atherosclerosis. 1998;140:99-270.

14. Gibbons RJ, Abrams J, Chatterjee K, et al. ACC/AHA 2002 guideline update for the management of patients with chronic stable angina-summary article: a report of the American College of Cardiology/American Heart Association Task Force on practice guidelines (Committee on the Management of Patients with Chronic Stable Angina). J Am Coll Cardiol. 2003;41:159-68.

15. Brugts JJ, de Maat M, Boersma E, et al. The Rationale and Design of the Perindopril Genetic Association Study (PERGENE): a pharmacogenetic analysis of angiotensin-converting enzyme inhibitor therapy in patients with stable coronary artery disease. Cardiovasc Drugs Ther. 2009;23:171-81.

16. Dagenais GR, Pogue J, Fox K, et al. Angiotensin convertingenzyme inhibitors in stable vascular disease without left ventricular systolic dysfunction or heart failure: a combined analysis of three trials. Lancet. 2006;368:581-8.

17. Deckers JW, Goedhart DM, Boersma E, et al. Treatment benefit by perindopril in patients with stable coronary artery disease at different levels of risk. Eur Heart J. 2006;27:796-801.

18. Brugts JJ, Knetsch AM, Mattace-Raso FU, et al. Renal function and risk of myocardial infarction in an elderly population: the Rotterdam study. Arch Intern Med. 2005;165:2659-65.

19. Brugts JJ, Boersma E, Chonchol M, et al. The cardioprotective effects of the angiotensin-converting enzyme inhibitor perindopril in patients with stable coronary artery disease are not modified by mild to moderate renal insufficiency: insights from the EUROPA trial. J Am Coll Cardiol. 2007;50:2148-55.

20. Brugts JJ, Ninomiya T, Boersma E, et al. The consistency of the treatment effect of an ACE-inhibitor based treatment regimen in patients with vascular disease or high risk of vascular disease: a combined analysis of individual data of ADVANCE, EUROPA, and PROGRESS trials. Eur Heart J. 2009;30:1385-94.

21. Danser AHJ, Schunkert H. Renin-angiotensin system gene polymorphisms: potential mechanisms for their association with cardiovascular diseases. Eur J Pharmacol. 2000;410:303-16.

22. Brugts JJ, de Maat M, den Uil CA, et al. Pharmacogenetics of ACE inhibition in stable coronary artery disease: steps towards tailored drug therapy. Curr Opin Cardiol. 2008;23:296-301.

23. Simon T, Verstuyft C, Mary-Kraue M, et al. Genetic determinants of response to clopidogrel and cardiovascular events. N Engl J Med. 2009;360:363-75.

24. The SEARCH collaborative group. SLCO1B1 variants and statininduced myopathy, a genome wide study. $\mathrm{N}$ Engl J Med. 2008;359:789-99. 
25. International Warfarin Pharmacogenetics Consortium, Klein TE, Altman RB, Eriksson N, et al. Estimation of the warfarin dose with clinical and pharmacogenetic data. $\mathrm{N}$ Engl J Med. 2009;19;360(8):753-64.

26. Brugts JJ, Isaacs A, Boersma E, et al. Genetic determinants of treatment benefit of the angiotensin-converting enzyme inhibitor perindopril in patients with stable coronary artery disease. Eur Heart J. 2010;31:1854-64.

27. Brugts JJ, Isaacs A, de Maat M, et al. A pharmacogenetic analysis of determinants of hypertension and blood pressure response to angiotensin-converting enzyme inhibitor therapy in patients with vascular disease and healthy subjects. J Hypertens. 2011;29(3):50919.

28. Remme WJ, Deckers JW, Fox KM, et al. for the EUROPA investigators. Secondary prevention of coronary disease with ACE inhibition — does blood pressure reduction with perindopril explain the benefits in EUROPA? Cardiovasc Drugs Ther. 2009;23(2):161-70.

29. Blood Pressure Lowering Treatment Trialists' Collaboration. Blood pressure-dependent and independent effects of agents that inhibit the renin-angiotensin system. J Hypertens. 2007;25:951-8.

30. Rodriguez-Granillo GA, Vos J, De Feyter PJ. Long-term effect of perindopril on coronary atherosclerosis progression (from the PERindopril's Prospective Effect on Coronary aTherosclerosis by Angiography and IntraVascular Ultrasound Evaluation [PERSPECTIVE] Study). Am J Cardiol. 2007;100:159-63.

31. Ceconi C, Fox KM, Ferrari R, et al. ACE inhibition with perindopril and endothelial function. Results of a substudy of the EUROPA study: PERTINENT. Cardiovasc Res. 2007;73:237-46.

32. Merino VF, Todiras M, Mori MA, et al. Predisposition to atherosclerosis and aortic aneurysms in mice deficient in kinin B1 receptor and apolipoprotein E. J Mol Med doi 10.1007/ s00109-009-0501-0
33. Luft FC. Aneurysm formation and bradykinin. J Mol Med. doi 10.1007/s00109-009-0517-5

34. Gainer JV, Morrow JD, Loveland A, et al. Effect of bradykininreceptor blockade on the response to angiotensin convertingenzyme inhibitor in normotensive and hypertensive subjects. $\mathrm{N}$ Engl J Med. 1998;339:1285-92.

35. Xu J, Carretero OA, Shesely EG, et al. The Kinin B1 receptor contributes to the cardioprotective effect of ace inhibitors and angiotensin receptor blockers. Exp Physiol. 2009;94:322-9.

36. Marin-Castaño ME, Schanstra JP, Neau E, et al. Induction of functional bradykinin $\mathrm{b}(1)$-receptors in normotensive rats and mice under chronic angiotensin-converting enzyme inhibitor treatment. Circulation. 2002;5:627-32.

37. Ignatovic $\mathrm{T}$, Tan F, Brovkovych V, et al. Novel mode of action of angiotensin i converting enzyme inhibitors: direct activation of the bradykinin receptor type I. J Biol Chem. 2002;277:16847-52.

38. Ignjatovic T, Stanisavljevic S, Brovkovych V, et al. Kinin B1 receptors stimulate nitric oxide production in endothelial cells: signaling pathways activated by angiotensin i-converting enzyme inhibitors and peptide ligands. Mol Pharmacol. 2004;66:1310-6.

39. Forten JP, Gobeil Jr F, Adam A, et al. Do angiotensin-converting enzyme inhibitors directly stimulate the kinin B1 receptor? Am J Physiol Heart Circ Physiol. 2003;285:H277-82.

40. Su JB, Hoüel R, Héloire F, et al. Stimulation of Bradykinin $B_{1}$ receptors induces vasodilation in conductance and resistance coronary vessels in conscious dogs. Circulation. 2000;101:184853.

41. Austinat M, Braeuninger S, Pesquero JB, et al. Blockade of bradykinin receptor B1 but not bradykinin receptor B2 provides protection from cerebral infarction and brain edema. Stroke. 2009;40:285-93. 